\title{
Percepção dos professores do entorno do Parque Paleontológico de São José de Itaboraí (RJ) sobre aspectos geológicos, paleontológicos e arqueológicos locais
}

\author{
Wellington Francisco Sá dos Santos \\ Universidade Federal do Rio de Janeiro, Centro de Ciências \\ Matemáticas e da Natureza, Instituto de Geociências, \\ Departamento de Geologia, Rio de Janeiro, RJ. \\ wfsasantos@gmail.com \\ Ismar de Souza Carvalho \\ Universidade Federal do Rio de Janeiro, Centro de Ciências \\ Matemáticas e da Natureza, Instituto de Geociências, \\ Departamento de Geologia, Rio de Janeiro, RJ. \\ ismar@geologia.ufrj.br
}

\begin{abstract}
TEACHERS PUBLIC UNDERSTANDING ABOUT THE SÃO JOSÉ DE ITABORAÍ PALEONTOLOGICAL PARK (RJ) CONCERNING LOCAL GEOLOGICAL, PALEONTOLOGICAL AND ARCHAEOLOGICAL ASPECTS. The geological heritage of São José de Itaboraí is represented by calcareous rocks rich in invertebrates and vertebrates fossils, specially the late Paleocene mammals. At this site there is also an important archaeological heritage represented by lithic artifacts. In this context, interviews were conducted with teachers of local public schools at the basic level, seeking to evaluate the level of understanding they pursue about geological, paleontological and archaeological aspects of the São José de Itaborai Paleontological Park. It was found that the teachers have little knowledge about the rocks, fossils and evidences of pre-history, however, the paleontological heritage is best perceived in relation to the archaeological one. This study may be used in geoconservation strategies, popular educational programs and interventions to attend geotourism. Citation:Santos W.F.S.dos, Carvalho I.S. 2013. Percepção dos professores do entorno do Parque Paleontológico de São José de Itaboraí (RJ) sobre aspectos geológicos, paleontológicos e arqueológicos locais. Terræ Didatica, 9(1):50-62. <http://www.ige.unicamp.br/terraedidatica/> .
\end{abstract}

KEYWORDS: São José de Itaboraí Paleontological Park; geological heritage; paleontological heritage; archaeological heritage

RESUMO O patrimônio geológico de São José de Itaboraí é representado por rochas calcárias ricas em fósseis de invertebrados e vertebrados, destacando-se os mamíferos do Paleoceno tardio. No local existe importante patrimônio arqueológico representado principalmente por artefatos líticos. Nesse contexto foram realizadas entrevistas com professores de escolas públicas locais de educação básica da região, buscando-se avaliar o nivel de conhecimento que possuem acerca dos aspectos geológicos, paleontológicos e arqueológicos do Parque Paleontológico de São José de Itaboraí. Verificou-se que os educadores têm pouco conhecimento das rochas, fósseis e das evidências humanas pré-históricas, no entanto, o patrimônio paleontológico é mais bem compreendido em relação ao arqueológico. O presente estudo pode ser utilizado em estratégias de geoconservação e do patrimônio, em programas de educação popular e em medidas para atender ao geoturismo.

PALAVRAS-CHAVE: Parque Paleontológico de São José de Itaboraí; patrimônio geológico; patrimônio paleontológico; patrimônio arqueológico 


\section{Introdução}

São José de Itaboraí é um bairro do município de Itaboraí (Estado do Rio de Janeiro), com cerca de 2.500 habitantes. No local existe pequena bacia sedimentar preenchida por rochas calcárias, que foram utilizadas, no período de 1933 a 1984, para a fabricação de cimento pela Companhia de Cimento Portland Mauá (Fig. 1). Durante esse período, a mineração teve grande importância no crescimento socioeconômico da região; o cimento produzido propiciou a construção de dois grandes empreendimentos brasileiros, como o estádio de futebol Mário Filho (Maracanã) e a ponte expressa Presidente Costa e Silva, que liga o Rio de Janeiro à cidade de Niterói (Santos 2010; Santos e Carvalho 2012b).

Em relação aos estudos científicos, a atividade de mineração revelou a existência de rico depósito fossilífero de invertebrados, vegetais, aves, anfíbios, répteis e, principalmente mamíferos, destacando-se os mamíferos do Paleoceno tardio, que se difundiram pela Terra após a extinção dos dinossauros há cerca de 57 milhões de anos. Essa característica única faz com que a bacia sedimentar seja conhecida na comunidade científica como o "berço dos mamíferos no Brasil" e, por esse motivo, considerada como patrimônio geológico. Devido à abundância, qualidade e diversidade dos fósseis, e de sua importância para o entendimento da evolução dos mamíferos sul-americanos, uma das Idades Mamíferos-Terrestres Sul-Americanas (SALMA), foi nomeada Itaboraiense por Marshall (1985), em referência à Bacia de São José de Itaboraí.

Todavia, a intensa atividade de mineração acarretou a destruição da maior parte dos afloramentos e os remanescentes encontram-se atualmente inundados ou cobertos por vegetação e rejeitos. Um lago se formou na bacia sedimentar após o fim da atividade mineradora, o que dificulta a continuidade dos estudos científicos. Por outro lado, o lago é atualmente utilizado para abastecer as comunidades do entorno, sendo gerenciado pela Cooperágua (cooperativa local sem fins lucrativos), por concessão da prefeitura de Itaboraí. Todavia não se sabe o tratamento dado a esta água, que possui grande concentração de carbonato de cálcio (Bergqvist et al. 2006). No local também existem vestígios (principalmente artefatos líticos e uma fogueira) do homem pré-histórico datados de $8.100 \pm 75$ AP (Antes do Presente). As evidências arqueológicas foram encontradas em um dos poucos afloramentos visíveis na bacia, denominado "Morro da Dinamite" (Fig. 2a) (Beltrão 2000).

Com o fim da extração do calcário para a fabricação do cimento, São José de Itaboraí e consequentemente Cabuçu e Curuzu, que são bairros vizinhos, entraram em processo de decadência social e econômica. Desde então, a região recebeu pouca atenção das organizações públicas e dos empreen-

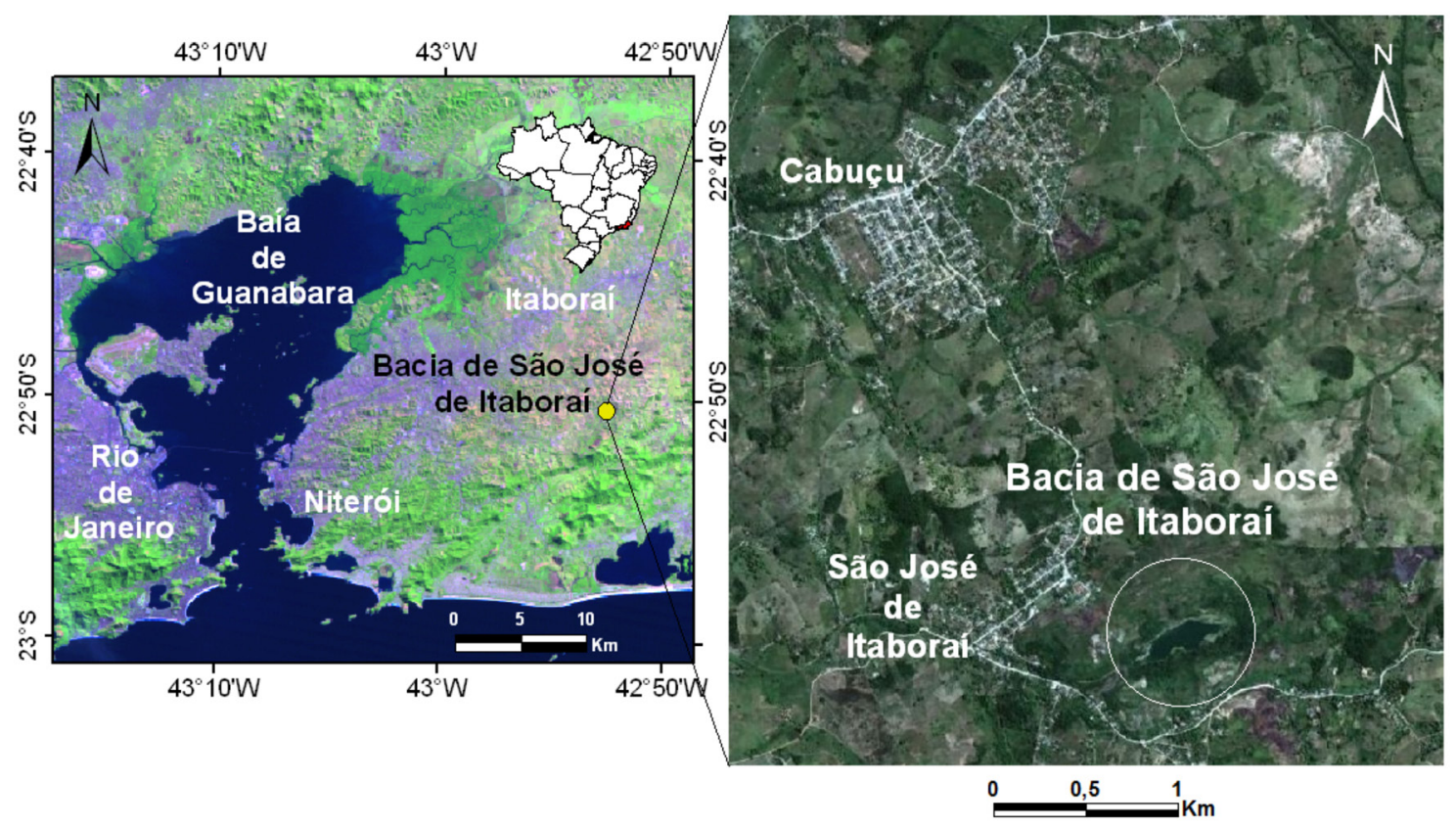

Figura 1 Localização geográfica da Bacia de São José de Itaboraí. Imagem obtida do satélite Landsat (2007) e Google Earth (2010). 
dedores do setor privado, tornando-se praticamente abandonada. Muitos pesquisadores da comunidade acadêmica do Rio de Janeiro lutaram pela criação de um parque paleontológico, com o intuito de garantir geoconservação, desenvolvimento de estudos científicos e promoção da educação e o treinamento da comunidade na questão ambiental. Assim, em 12 dezembro de 1995, foi criado o Parque Paleontológico de São José de Itaboraí, pelo governo.

Após 17 anos de funcionamento são poucas as melhorias realizadas no parque paleontológico. O local foi delimitado no ano de 2005, contudo, a cerca que delimita o parque encontra-se cortada em alguns pontos. No interior da instituição existe um banheiro público destinado aos visitantes, um deck para a visualização da lagoa (Fig. 2a), o Centro de Referência Ambiental, Paleontológico e Arqueológico, construído numa antiga instalação da Companhia de Cimento Portland Mauá (Fig. 2b), além de uma réplica de preguiça gigante (Fig. 2c). No centro acham-se expostas rochas e artefatos líticos do homem pré-histórico encontrados na bacia. Entretanto, os fósseis não estão expostos no parque, foram introduzidos em coleções de museus e instituições científicas, já que o parque paleontológico não possui um local adequado para guardá-los e nem uma sala de preparação dos mesmos. Segundo Souza (2009), o fato de os fósseis não estarem no parque pode vir a ser um dos complicadores para a criação de identidade das populações locais e demais visitantes com a instituição. No entanto, por estarem próximos aos pesquisadores propiciou a publicação de centenas de trabalhos, tornando-se uma questão ambígua.

Apesar dos problemas estruturais, o Parque Paleontológico de São José de Itaboraí é muito visitado, principalmente, por alunos de escolas locais e estudantes universitários interessados no conhecimento da evolução geológica do estado do Rio de Janeiro, caracterizando assim o geoturismo na região. Todavia, esses dados não vêm sendo quantificados pela instituição. Um canal importante de comunicação entre os pesquisadores e a comunidade local se dá pela concessão de bolsas do projeto "jovens talentos" para adolescentes do ensino médio do Colégio Estadual Visconde de Itaboraí (CEVI), localizado no centro de Itaboraí, que fica distante do parque. Os jovens são treinados em geologia, paleontologia, arqueologia e meio ambiente por professores da Universidade Federal do Rio de Janeiro e Universidade Estadual do Rio de Janeiro, com o intuito de se transformarem em guias e guardiões do parque. Os alunos se reúnem aos sábados nas dependências do parque e realizam atividades educativas, artesanatos e modelagem, supervisionados pelos pesquisadores (Rodrigues et al. 2006). No entanto, segundo Souza (2009), este trabalho educacional é árduo e não possui um retorno imediato. Além disso, a existência de pessoas que residem irregularmente no parque e a falta de recursos para reassentá-las dificultam as propostas de melhoria da instituição (Fig. 2d).

Atualmente, o Parque Paleontológico de São José de Itaboraí está em processo de revitalização, por meio de projeto coordenado pelo Instituto Virtual de Paleontologia (IVP) da Fundação de Amparo à Pesquisa do Estado do Rio de Janeiro (FAPERJ) e Prefeitura Municipal de Itaboraí. A revitalização inclui a reforma do Centro de Referência Ambiental, Paleontológico e Arqueológico, a recuperação da área degradada por meio de um reflorestamento, a criação de uma rede de trilhas interpretativas, de um museu paleontológico, um laboratório de pesquisas, um núcleo de educação e aprendizagem profissional, um alojamento para pesquisadores, laboratórios de informática, salas de vídeo, laboratório de preparação de fósseis, além de prover infraestrutura básica no suporte às atividades de visitação (Velloso e Almeida, 2006). Dessa forma, o projeto de revitalização do Parque Paleontológico de São José de Itaboraí poderá acarretar um novo impulso social e econômico na região por meio do estímulo ao geoturismo.

Santos (2010), Santos e Carvalho (2011a), Santos e Carvalho (2011b) e Santos e Carvalho (2012c) realizaram entrevistas com a população de São José de Itaboraí, Cabuçu e com os professores da região buscando entender a percepção que possuem do parque paleontológico. Verificaram que os entrevistados conhecem o parque paleontológico, a maioria já o visitou, entretanto, não se sentem convidados a participar dos projetos da instituição, como por exemplo, o "projeto jovens talentos para a ciência". Acreditam que o local está abandonado, pois é carente em atrativos e infraestrutura de atendimento aos visitantes. Devido à demora na efetivação das propostas de revitalização, os habitantes locais encontram-se desconfiados dos interesses dos responsáveis pelo parque e acreditam que a instituição serve apenas para "lavagem de dinheiro". Além disso, comentaram que a população não se interessa pela temática e a maioria não participa da preservação local.

Buscando-se entender a percepção populacio- 

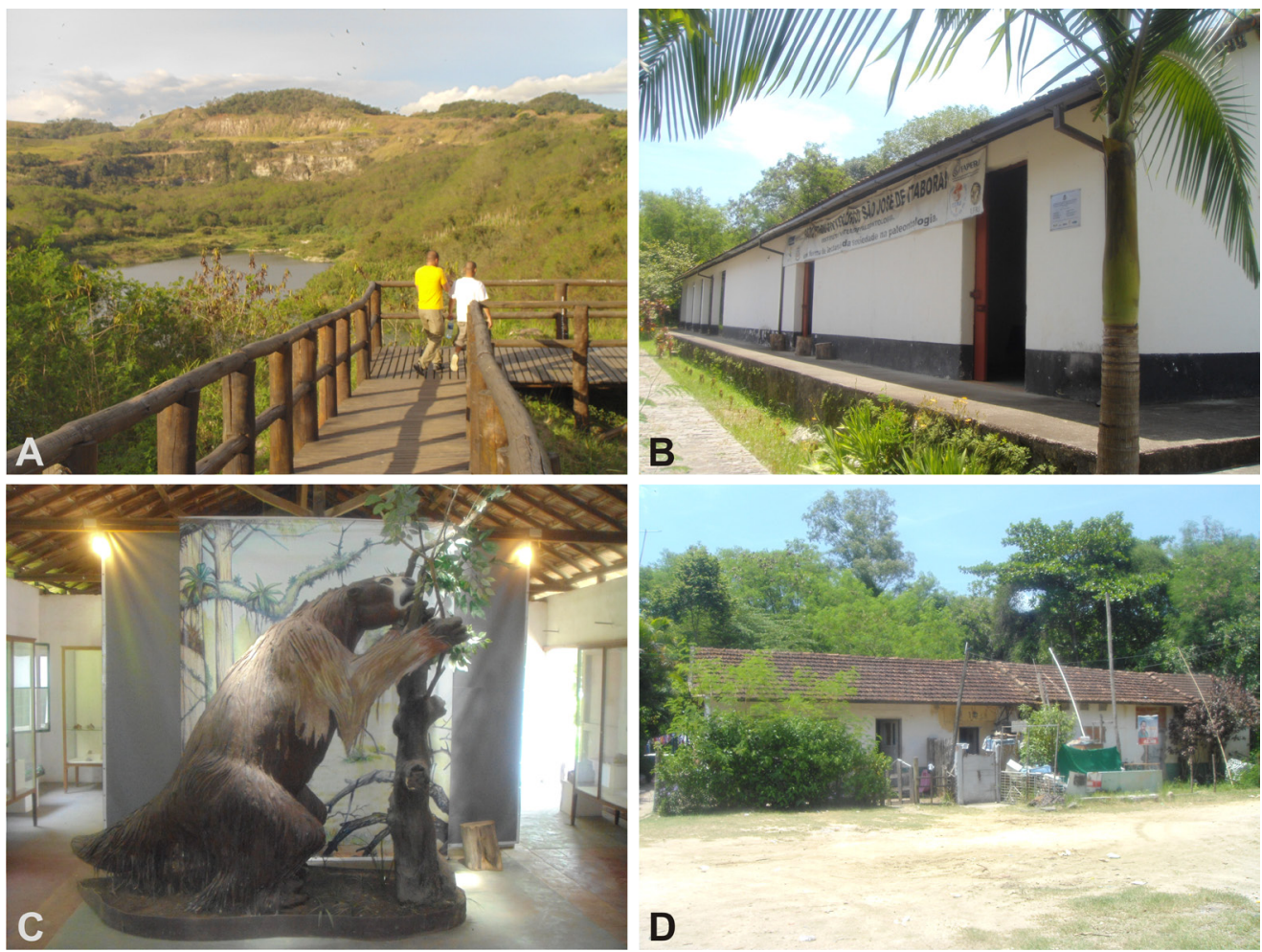

Figura 2 Parque Paleontológico de São José de Itaboraí. A, Bacia de São José de Itaboraí. Note o lago formado na depressão deixada pela extração de calcário, o deck construído para a visualização da bacia e ao fundo o Morro da Dinamite, local onde foram encontrados vestígios de ocupação pré-histórica (fevereiro, 2013). B, Centro de Referência Ambiental, Paleontológico e Arqueológico do Parque Paleontológico de São José de Itaboraí (fevereiro, 2013). C, Visão interna do Centro de Referência Ambiental, Paleontológico e Arqueológico do Parque Paleontológico de São José de Itaboraí, destacando-se a réplica de uma preguiça gigante (fevereiro, 2013). D, Ocupação irregular em antigas instalações da Companhia Nacional de Cimento Portland Mauá (fevereiro, 2013).

nal dos potenciais efeitos socioeconômicos do geoturismo, Santos (2010), Santos e Carvalho (2011c), Santos e Carvalho (2011d), Santos e Carvalho (2012a) e Santos e Carvalho (2012d) verificaram que os moradores de São José de Itaboraí, Cabuçu e os professores da região acreditam na intensificação do geoturismo com a revitalização do parque paleontológico e confiam no aumento de empregos na região, principalmente no comércio de alimentos e em funções no interior do parque (guias turísticos, limpeza, segurança). Comentaram que a pavimentação das estradas, os transportes públicos e o saneamento básico necessitam de melhorias para atender aos visitantes e as populações locais e disseram também que o lixo, a violência e o vandalismo ao patrimônio são as principais ameaças para a região com o aumento do geoturismo.

Nesse contexto, foram realizadas entrevistas com os professores da rede pública do entorno do Parque Paleontológico de São José de Itaboraí buscando-se entender a percepção que possuem dos aspectos geológicos, paleontológicos e arque- ológicos locais. Assim, saberemos quais as medidas necessárias de valorização e divulgação do patrimônio de São José de Itaboraí junto aos educadores da região. Vimos que um trabalho de conscientização é feito apenas com os estudantes do ensino médio de uma escola do centro de Itaboraí, que fica afastada do parque paleontológico, dexando longe das iniciativas os estudantes de outros colégios, os professores e a população em geral. No entanto, na teoria do construtivismo educacional a aprendizagem se dá em conjunto entre alunos e professores. Os resultados da pesquisa podem ser aplicados em programas de educação popular, em estratégias de geoconservação do patrimônio geológico e arqueológico e em projetos para atender ao geoturismo.

\section{Aspectos metodológicos}

Foram realizadas 100 entrevistas com abordagens diretas e de maneira aleatória com os professores da rede pública do entorno do Parque Paleontológico de São José de Itaboraí. Elaborou-se 
um questionário com questões pré-estabelecidas e temas voltados à percepção dos professores em relação aos aspectos geológicos, paleontológicos e arqueológicos da região, possibilitando uma análise quantitativa e qualitativa dos dados. Algumas das questões apresentavam respostas fechadas, já que neste caso a intenção era a obtenção de dados quantitativos. Entretanto, outras questões eram de caráter aberto, na busca de informações qualitativas. Os educadores foram questionados nas escolas em que lecionavam, geralmente no intervalo das aulas e apenas respondiam as questões, que eram interpretadas e transcritas pelo entrevistador.

As entrevistas ocorreram entre os dias $30 \mathrm{de}$ outubro e 12 de novembro de 2009. Visitou-se a Escola Municipal Promotor Luiz Carlos Caffaro (30 entrevistados), Escola Municipal Gastão Dias de Oliveira (13 entrevistados), Escola Municipal Coronel Antonio Leal (7 entrevistados), Escola Municipal Pimentel de Carvalho (11 entrevistados), Escola Estadual Lucas da Silva (8 entrevistados), Creche Escola Municipal Luiz Antonio Mira de Souza (7 entrevistados), Escola Municipal Professora Maria Cristina Soares Fróes (5 entrevistados) e Colégio Estadual Francesca Carey (19 entrevistados). Todas as instituições de ensino localizam-se no município de Itaboraí e distam no máximo $12 \mathrm{~km}$ da entrada do parque paleontológico, estando dentro de um mesmo contexto regional, evitando-se desta forma disparidades nas respostas aos questionários.

Inicialmente os professores foram indagados sobre as rochas existentes na Bacia de São José de Itaboraí. Posteriormente se tinham conhecimento do conceito de fóssil, se sabiam da existência de fósseis em São José de Itaboraí e sobre quais grupos de organismos se referiam. Por fim, buscou-se avaliar se os educadores tinham noção da existência de vestígios do homem pré-histórico em São José de Itaboraí e, se sabiam quais eram os vestígios (Tab. 1).

\section{Perfil dos educadores}

Dentre os professores consultados 11\% são do sexo masculino e $89 \%$ do sexo feminino. A faixa etária desses indivíduos possui entre 21 e 60 anos. Destes, $44 \%$ possuíam de 21 a 35 anos, $50 \%$ de 36 a 50 anos e $5 \%$ de 51 a 60 anos. Apenas um entrevistado não revelou a idade. Um total de $71 \%$ dos professores reside em diferentes localidades de Itaboraí, 23\% em diferentes bairros de São Gonçalo e os outros $6 \%$ habitam distintos municípios do Rio de Janeiro. Entre os bairros de Itaboraí se destacam Cabuçu, onde moram 17\% dos professores entrevistados e São José de Itaboraí com 13\%, ambos do $6^{\circ}$ distrito do município, no qual cinco das oito escolas visitadas estão inseridas.

Em relação à escolaridade, 23\% dos professores possuem o ensino médio completo, $7 \%$ o ensino superior incompleto, 36\% completaram o ensino superior e 34\% finalizaram alguma pós-graduação. Levando-se em consideração a faixa salarial dos educadores, 64\% recebem de um a dois salários mínimos e meio, $27 \%$ de três a quatro salários e meio e $9 \%$ ganham de cinco a oito salários e meio. Entre os que recebem melhores salários estão incluídos os professores que possuem pós-graduação.

\section{Aspectos geológicos, paleontológicos e arqueológicos de São José de Itaboraí}

Essa etapa da pesquisa buscou entender a consciência dos professores da rede pública do entorno do Parque Paleontológico de São José de Itaboraí em relação ao patrimônio geológico, paleontológico e arqueológico da área. Questões relacionadas a rochas, fósseis e vestígios dos seres humanos pré-históricos serão avaliadas a seguir.

Tabela 1 Questionário que analisa a percepção dos professores em relação aos aspectos geológicos, paleontológicos e arqueológicos de São José de Itaboraí.

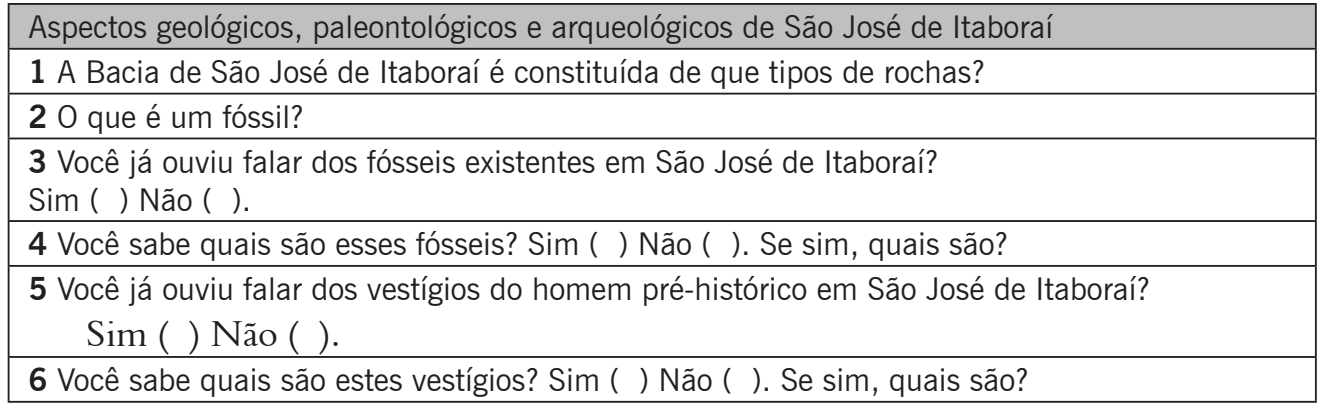




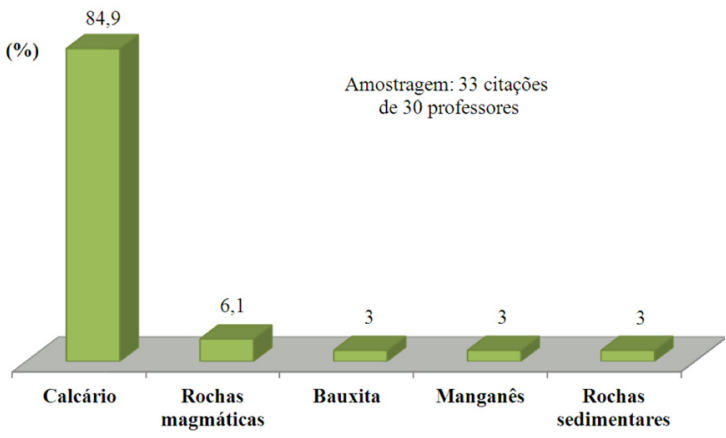

Figura 3 Opiniões dos professores acerca dos tipos de rochas existentes na Bacia de São José de Itaboraí. Universo de 33 citações de 30 entrevistados (30/10/09 a 12/11/09).

\section{Percepção dos professores em relação às rochas existentes em São José de Itaboraí}

Esta abordagem da pesquisa testou o conhecimento dos professores acerca das rochas existentes na Bacia de São José de Itaboraí. A primeira questão procurou avaliar se os entrevistados sabiam quais eram as rochas que preenchiam a bacia sedimentar e, $30 \%$ dos 100 professores sabiam, enquanto que $70 \%$ não tinham conhecimento dessa temática. Então, mesmo com a existência de uma grande empresa que explotara rochas calcárias comercialmente para a fabricação de cimento em São José de Itaboraí, com grande contribuição na geração de emprego e renda e na melhoria da infraestrutura da região (Santos e Carvalho 2012b), foram poucos os entrevistados que reconheciam a presença dessa e de outras rochas na área.

Dentre os 30 entrevistados houve 33 opiniões diferenciadas sobre os tipos de rochas existentes na Bacia de São José de Itaboraí. Dessa maneira, percebe-se (Fig. 3) que $84,9 \%$ das 33 citações dos professores referem-se à presença de rochas calcárias no local. Essa parcela dos educadores está mais sensível às questões geológicas e históricas da região. Entre as rochas calcárias encontradas destacam-se o calcário travertino, de origem química (Fig. 4a), o calcário cinzento de origem clástica (Fig. 4b) e calcário oolítico (Fig. 4c) e pisolítico (Fig. 4d) que são associados ao travertino e a fontes termais. Uma porcentagem de $6,1 \%$ das 33 citações dos professores destinou-se à presença de rochas magmáticas no local. São rochas presentes na bacia e em seu entorno, representadas por ankaramitos (rocha vulcânica) (Fig. 4e) e granitos (rocha plutônica) (Fig. 4f).

A figura 3 mostra que 3\% das 33 citações dos professores se referiram à presença de bauxita na Bacia de São José de Itaboraí, o que não se comprova. A bauxita é a principal fonte comercial de alumínio e não existe na Bacia de São José de Itaboraí (Guerra e Guerra 2009). Um total de 3\% das 33 citações dos professores assinala a presença de depósitos de manganês em São José de Itaboraí, o que não é verdade. O manganês é um metal muito abundante na crosta terrestre, encontrado em centenas de minerais na natureza, sendo muito utilizado para a fabricação de aço e de pilhas elétricas (Guerra e Guerra 2009). Contudo, não se encontra na Bacia de São José de Itaboraí. Para finalizar, $3 \%$ das 33 citações dos professores calcaram-se na presença de rochas sedimentares na Bacia de São José de Itaboraí, as quais não foram especificadas.

\section{Conhecimento dos professores a respeito do conceito de fóssil}

A figura 5 aborda o conhecimento dos professores da rede pública em relação ao conceito de fóssil. Numa linguagem simples, os fósseis são restos (ossos, conchas e dentes) e vestígios (pegadas, ovos, fezes e marcas de repouso) de diferentes
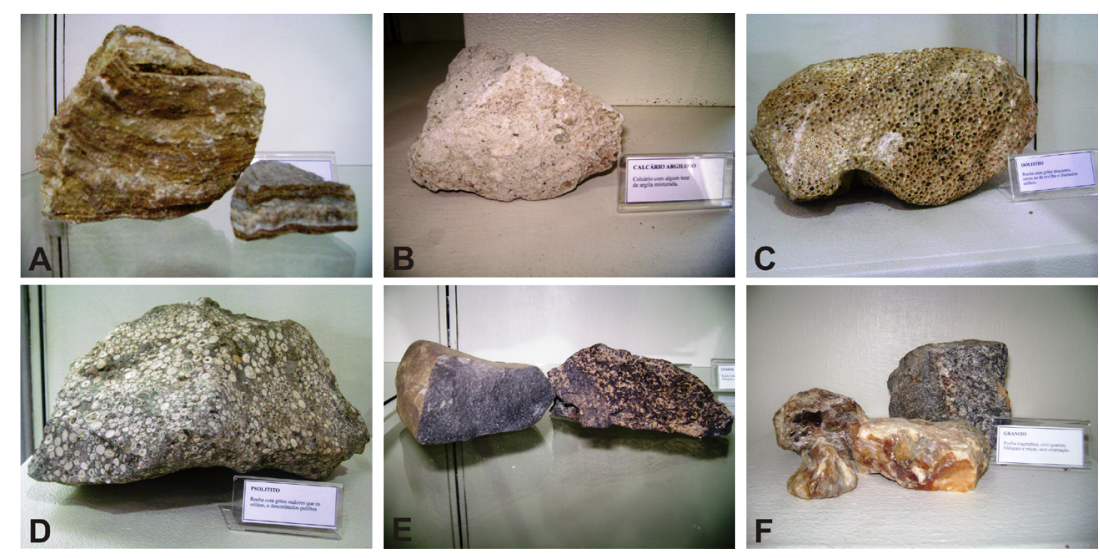

Figura 4 Rochas encontradas na Bacia de São José de Itaboraí e expostas no Centro de Referência Ambiental, Paleontológico e Arqueológico. A, Amostras de calcário travertino (fitado/bandado) de origem química (precipitação de carbonatos). B, Amostra de calcário argiloso de origem clástica. C, Amostra de calcário oolítico. D, Amostra de calcário pisolítico. E, Ankaramito. Rocha magmática vulcânica. F, Granito. Rocha magmática plutônica. 
organismos pré-históricos (+ de 11.000 anos), como por exemplo, animais, vegetais, fungos e bactérias, que se encontram preservados em rochas sedimentares e algumas metamórficas de baixo grau e ígneas eruptivas. Isso se dá por meio de fatores naturais que atuam na preservação, como rápido soterramento e sedimentos do tamanho de argila (menos de 0,002 mm), ausência de oxigênio e ação bacteriana que são responsáveis pela decomposição da matéria orgânica e, de condições que favoreçam a fossilização, como a composição química e estrutural do esqueleto, o modo de vida dos organismos e as condições químicas do meio, que somados determinam o modo de fossilização (Carvalho 2000).

Assim, buscou-se entender o conhecimento que os professores possuem em relação ao objeto de estudo da Paleontologia, uma vez que os fósseis são de grande interesse para o geoturismo na área do entorno do Parque Paleontológico de São José de Itaboraí. As respostas foram muito generalizadas, mas pôde-se agrupá-las para uma compreensão geral do nível de entendimento que os entrevistados possuem sobre este conceito. De maneira comparativa e levando em consideração que dentre todos os educadores, somente o processo de mineralização (permineralização) foi citado como responsável pela fossilização considerou-se na pesquisa, como um conceito correto de fóssil, os restos e vestígios de organismos pré-históricos, que sofreram um processo natural de mineralização e ficaram preservados, principalmente, nas rochas sedimentares.

Pela análise da figura 5 percebe-se que boa porcentagem dos professores (47\%) acredita que os fósseis sejam restos de animais pré-históricos. De maneira geral, os educadores explicaram que os restos de animais foram preservados em rochas, estavam enterrados antes de serem achados e sofreram processo de mineralização (petrificação). Contudo, não consideraram os restos de vegetais e de outros seres vivos, como evidências de organismos (icnofósseis), como por exemplo, tubos (invetebrados), pegadas, fezes (coprólitos) e ovos de vertebrados, nem o tipo de rocha em que os fósseis foram preservados, o que deixa o conceito incompleto.

Em relação ao tópico restos de animais e vegetais (Fig. 5) averígua-se que $12 \%$ dos professores possuem noção de que além dos animais, também os vegetais podem se fossilizar. Explanaram que estes restos de animais e vegetais foram soterrados e preservados em rochas pelo processo de mineralização (petrificação).

Apenas $10 \%$ dos professores acreditam que os fósseis sejam restos orgânicos (Fig. 5). De maneira geral os educadores comentaram da preservação desses restos orgânicos na natureza, geralmente em áreas sedimentares. Creem que os fósseis retratam características de antigos ambientes e são preservados pelas condições locais. Entendem que foram extintos ou ainda existem e que são encontrados por meio de escavações. Os entrevistados não comentaram sobre os vestígios dos organismos e nem o processo de mineralização (petrificação), porém, um fato interessante é terem abordado a importância do estudo dos fósseis para caracterização do paleoambiente em que os seres viviam. $\mathrm{Na}$ figura 5 verifica-se que $2 \%$ dos professores associaram os fósseis a restos e vestígios de animais e vegetais. Somente $4 \%$ dos educadores chegaram próximo do correto conceito de fóssil estipulado na pesquisa, quando o associaram a restos e vestígios de organismos em geral. Esta porcentagem de entrevistados acredita que estes restos e vestígios de organismos são encontrados em rochas sedimentares. Entretanto, não comentaram sobre o processo de mineralização.

Alguns educadores consideraram os fósseis como sendo restos de seres humanos e rochas, o que revela a confusão que fazem com os conceitos geológicos, paleontológicos e arqueológicos. A figura 5 mostra que $7 \%$ dos professores creem que os fósseis sejam restos de animais e de seres humanos, $2 \%$ acreditam que são restos e vestígios

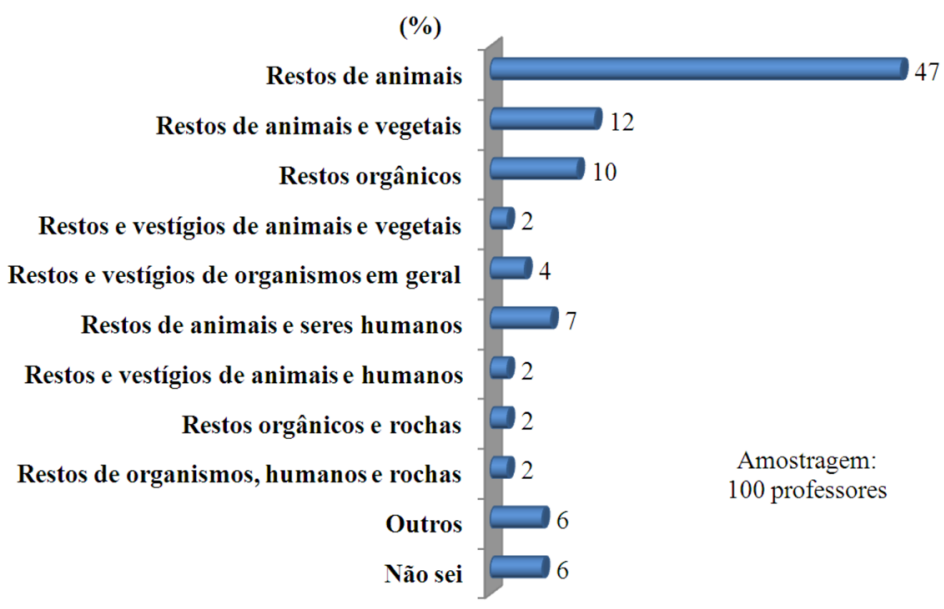

Figura 5. Conhecimento dos professores sobre o conceito de fóssil. Universo de 100 entrevistados (30/10/09 a 12/11/09). 
de animais e de seres humanos, $2 \%$ que acham que são os restos orgânicos e as rochas e $2 \%$ que compreendem que os fósseis sejam restos de organismos, seres humanos e rochas.

O tópico outros $(6 \%)$ compreende apenas as opiniões dos professores sobre o conceito de fóssil, que não se encaixaram em nenhum dos temas abordados anteriormente. Entre estes temos os que acreditam que os fósseis são fragmentos de "coisas" que não mais existem, resíduos de índios com mais de 100 anos, animais que estão em decomposição e ossos de dinossauros. Na figura 5 apura-se que $6 \%$ dos educadores não souberam explicar o conceito de fóssil.

Nesse contexto, fica claro o pouco conhecimento dos professores em relação ao conceito de fóssil, pois não houve uma explanação correta, sendo abordado pelos entrevistados de maneira fragmentada. Além disso, alguns educadores consideraram incorretamente os fósseis como rochas e ossos humanos.

\section{Percepção dos professores acerca dos fósseis existentes em São José de Itaboraí}

Constou-se que, 87\% dos 100 entrevistados sabiam da existência de fósseis em São José de Itaboraí, enquanto que $13 \%$ nunca ouviram falar dos restos e vestígios de organismos na área. Isso mostra que os educadores estão sensíveis à presença do patrimônio paleontológico na região. Dentre os 87 professores cientes da existência de fósseis em São José de Itaboraí, 60,9\% sabiam quais eram os organismos fósseis, enquanto que 39,1\% não sabiam.

\section{Opiniões dos professores em relação aos tipos de organismos fósseis encontrados em São José de Itaboraí}

A figura 6 analisa as opiniões dos professores acerca dos tipos de organismos fósseis encontrados na Bacia de São José de Itaboraí. Desta etapa da pesquisa participaram os entrevistados que sabiam quais eram os fósseis descobertos na região. Dessa forma, ocorreram 89 citações de 53 educadores.

Dos vários grupos fósseis coletados na Bacia de São José de Itaboraí, os gastrópodes (caramujos-moluscos) são os únicos que provém, em sua quase totalidade, da camada de calcário que recobria o fundo da Bacia de São José de Itaboraí de idade Paleoceno tardio (Klein e Rodrigues-Francisco 1981a, Klein e Rodrigues-Francisco 1981b). Oca- sionalmente nesta camada foram também encontrados restos de plantas, répteis e alguns mamíferos, como o Carodnia vieirai. Contudo, a grande maioria destes, além de anfíbios, aves e mamíferos marsupiais foram encontrados em depósitos de preenchimento de fendas e canais de dissolução do calcário, também de idade Paleoceno tardio (Paula-Couto 1949, Souza-Cunha 1982). Alguns ossos fragmentados e friáveis de mastodonte, preguiça gigante e tartarugas (quelônios) de idade eocênica/oligocênica foram também encontrados em pequena área, $100 \mathrm{~m}$ a sul da bacia sedimentar (Price e Campos 1970, Bergqvist et al. 2008).

A figura 6 mostra que os fósseis de preguiça gigante obtiveram $29,2 \%$ das 89 citações dos professores. Como visto anteriormente, uma réplica foi construída e está exposta no Centro de Referência Ambiental, Paleontológico e Arqueológico do Parque Paleontológico de São José de Itaboraí (Fig. 2c). O objetivo é atender ao geoturismo e conscientizar as comunidades locais sobre a importância do patrimônio geológico da região, já que os fósseis de preguiça gigante são os que possuem maior apelo local.

A figura 6 mostra que os moluscos (caramujos) obtiveram $14,6 \%$ das 89 citações. Um total de $14,6 \%$ das 89 citações dos educadores destinou-se aos fósseis de dinossauros. No entanto, não foram encontrados fósseis de dinossauros na Bacia de São José de Itaboraí. Santos e Carvalho (2008) realizaram entrevistas com os moradores de Peirópolis, um bairro de aproximadamente 300 habitantes do município de Uberaba (Minas gerais, Brasil) inserido na Bacia Bauru, rica em fósseis de dinossauros, buscando a análise da percepção da população local acerca do conceito de fóssil. Dos 100 moradores entrevistados, $22 \%$ acreditavam que um fóssil se tratava de ossos de dinossauros. Isso mostra a grande influência da palavra "dinossauro" no imaginário popular, que muitas vezes é considerada como sinônimo de fósseis e, também, de Paleontologia.

$\mathrm{Na}$ figura 6 percebe-se que, $7,9 \%$ das 89 citações feitas pelos professores abordavam, com quatro citações, os mamíferos em geral, sem especificação de nenhum indivíduo e, entre os específicos tivemos, com uma citação cada, o ancestral do rinoceronte, as capivaras e os morcegos. Nenhum destes fósseis foi encontrado na Bacia de São José de Itaboraí. Outro fóssil que obteve citações consideráveis foi o da "anta gigante" (Carodnia vieirai) (Fig. 6), sendo reconhecido como o maior mamífero paleocênico de São José de Itaboraí. Então, a 


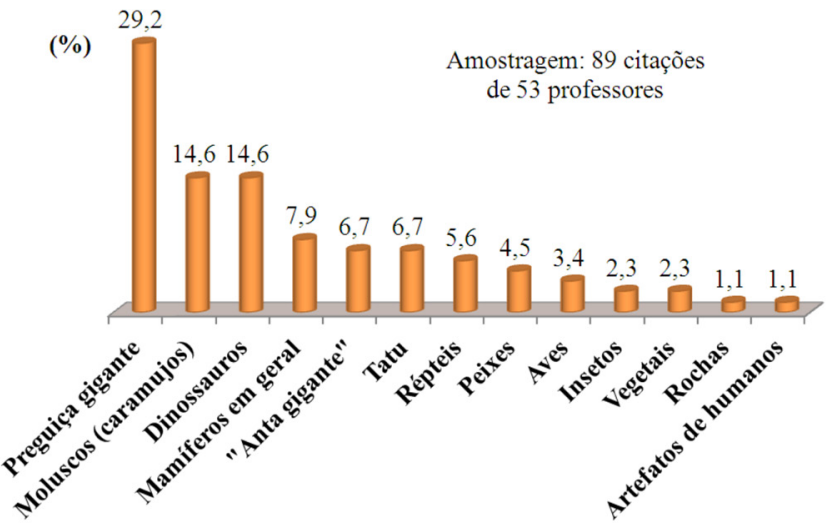

Figura 6. Opiniões dos professores acerca dos tipos de organismos fósseis encontrados na Bacia de São José de Itaboraí. Universo de 89 citações de 53 entrevistados (30/10/09 a 12/11/09).

“anta gigante" obteve $6,7 \%$ das 89 citações e, dentre os mamíferos do Paleoceno tardio, apresentou uma boa porcentagem de indicações. Assim, este fóssil também é especial para ser usado para o geoturismo e educação popular (Fig. 7a).

$\mathrm{Na}$ figura 6 verifica-se que $6,7 \%$ das 89 citações dos educadores se baseavam nos fósseis de tatu. O tatu é um símbolo do parque paleontológico, desenhado em placas de sinalização, tanto em Cabuçu, quanto em São José de Itaboraí (Fig. $7 b)$. Nesse sentido, esperava-se uma boa porcentagem de indicações, no entanto, o tatu foi pouco citado. Os fósseis de répteis obtiveram 5,6\% das 89 citações (Fig.6). Na Bacia de São José de Itaboraí foram descobertos fósseis de crocodilos e são os mais comuns entre os répteis. Os fósseis de cobras e lagartos, também foram encontrados, bem como de tartarugas (quelônios).

O paleolago existente em São José de Itaboraí durante o Paleoceno tardio era rico em carbonato de cálcio e possuía águas termais com temperaturas elevadas. Desse modo, nenhum fóssil de peixe ou animal bentônico foi encontrado na Bacia de São José de Itaboraí (Bergqvist et al. 2006). Mesmo assim, avaliando-se a figura 6 repara-se que, $4,5 \%$ das 89 citações dos professores destinaram-se à presença de fósseis de peixes na localidade. Esta afirmação pode estar associada à presença de um lago atual na Bacia de São José de Itaboraí, fazendo com que os entrevistados acreditem que existam fósseis de peixes na região (Fig. 2a).

As aves representaram 3,4\% das 89 citações dos educadores. Na figura 6 verifica-se que os fósseis de insetos abrangeram 2,3\% das 89 referências. Entretanto, nenhum fóssil de inseto foi encontrado na Bacia de São José de Itaboraí. Os fósseis de vegetais receberam $2,3 \%$ das 89 citações. Nenhum anfíbio foi citado pelos entrevistados e são os fósseis mais raros de serem encontrados na Bacia de São José de Itaboraí. Os mamíferos marsupiais também não foram lembrados e são os mais diversificados na bacia.

As rochas foram consideradas como organismos fósseis em 1,1\% das 89 citações dos professores (Fig. 6). Esse acontecimento pode ser explicado pelo fato dos fósseis sofrerem um processo natural de mineralização e perda da matéria orgânica original. Então, era de se esperar que algum entrevistado confundisse os fósseis com rochas. Os artefatos de antigos seres humanos obtiveram $1,1 \%$ das 89 citações dos educadores (Fig. 6). Tanto os ossos humanos, quanto os artefatos dos seres humanos não são considerados fósseis e, são objetos de estudo da Arqueologia. Isso comprova novamente a confusão que alguns entrevistados fazem com os conceitos
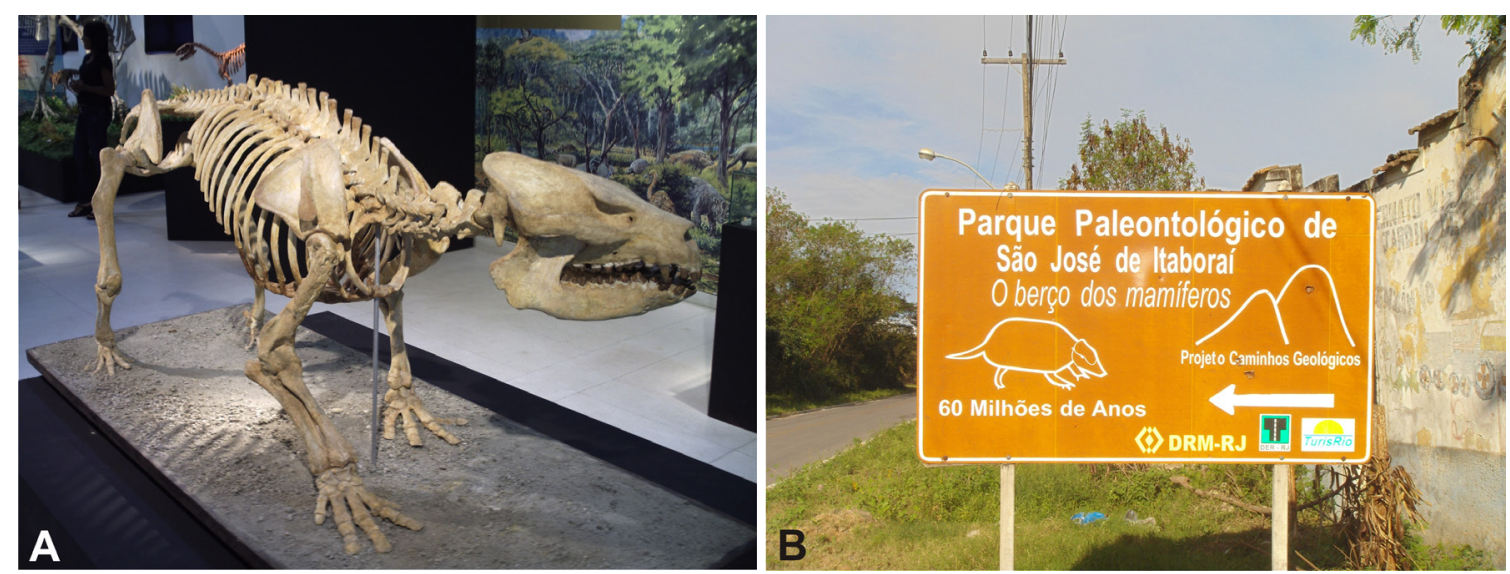

Figura 7. A, Réplica do mamífero Carodnia vieirai, coleção do Departamento de Geologia, UFRJ (fevereiro, 2010). B, Placa de sinalização do "Projeto Caminhos Geológicos" indicando a entrada do Parque Paleontológico de São José de Itaboraí. Notar o desenho de um tatu que é o símbolo do parque (fevereiro, 2013). 
de Geologia, Arqueologia e Paleontologia, expondo a necessidade de conscientização populacional.

Pela análise da figura 6 ocorreu de um modo geral, uma porcentagem de citações menor para os fósseis existentes na Bacia de São José de Itaboraí, como por exemplo, os répteis, as aves e os vegetais, além de nenhuma citação para os anfíbios e mamíferos marsupiais, em comparação com as porcentagens das citações dos fósseis que não são encontrados na região, como os dinossauros, peixes e insetos.

\section{Noção dos professores acerca dos vestígios do homem pré-histórico em São José de Itaboraí}

Apenas $12 \%$ dos professores sabiam dos vestígios do homem pré-histórico em São José de Itaboraí; a maioria (88\%) desconhecia o assunto. Esse fato é extremamente preocupante, na medida em que grande parte dos professores reside no município de Itaboraí (71\%), leciona em escolas que distam no máximo $12 \mathrm{~km}$ do parque paleontológico e, pelo bom grau escolar que possui e acesso que tem aos meios de comunicação, deveria conhecer o patrimônio da região, não só o geológico e paleontológico, mas o arqueológico, histórico e cultural.

Dentre os 12 professores que conheciam os vestígios humanos pré-históricos, 58,3\% sabiam quais eram as evidências e $41,7 \%$ não tinham ciência do assunto. Posteriormente procurou-se interpretar, dos professores que sabiam dos vestígios humanos pré-históricos, quais eram as evidências. Assim, ocorreram 8 citações de apenas 7 professores (Fig. 8). Um total de $50 \%$ das 8 citações referiu-se a artefatos líticos, 37,5\% a ossos humanos e 12,5\% a utensílios feitos de cerâmica. Os vestígios do homem pré-histórico na Bacia de São José de Itaboraí são artefatos líticos e restos de fogueira. Ossos humanos e utensílios de cerâmica não foram achados no local. Os artefatos líticos encontrados na bacia sedimentar eram utilizados para gravar (buris), raspar, cortar (facas de dorso), bater (talhadeiras), cortar e furar (faca-perfurador) e para fazer pontas de lança (Fig. 9) (Beltrão 2000). Desse modo, percebe-se que, de 100 professores, apenas sete sabiam quais eram os vestígios do homem pré-histórico e desses, ocorreram somente quatro citações corretas direcionadas a artefatos líticos.

Souza (2009) afirmou em estudo sobre os aspectos socioeconômicos e patrimoniais relacionadas ao Parque Paleontológico de São José de Itaboraí, que os conceitos arqueológicos são mais bem

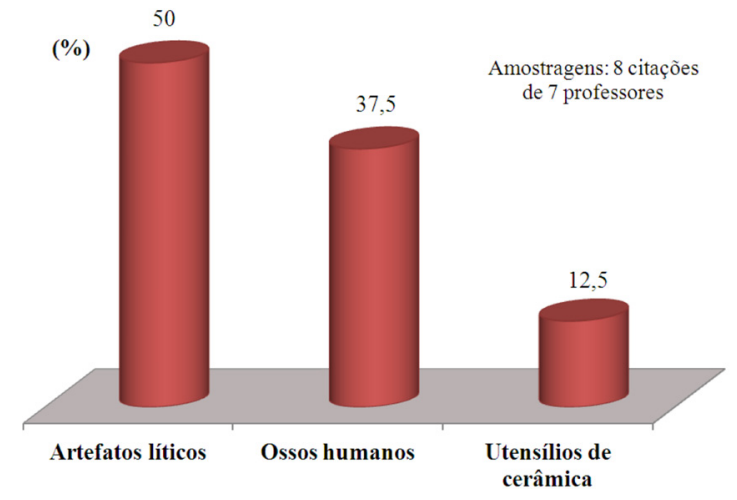

Figura 8. Opiniões dos professores acerca dos tipos de vestígios do homem-pré-histórico achados na Bacia de São José de Itaboraí. Universo de 8 citações de 7 entrevistados (30/10/09 a 12/11/09).

apreendidos do que os paleontológicos na região. A autora realizou 100 entrevistas com os moradores de São José de Itaboraí (21\%), Cabuçu (28\%), Curuzu (21\%), além do centro de Itaboraí (30\%).

Duas perguntas do questionário podem ser analisadas. Na primeira, a autora questionou os entrevistados sobre os valores que o parque possui, com respostas pré-definidas, cabendo a escolha aos participantes. Os valores mais vezes citados, em ordem hierárquica, foram o histórico (24\%), paleontológico (21\%), lazer (14\%), geológico (14\%), arqueológico (12\%), econômico (11\%), nenhum (3\%) e outro (1\%). Na segunda indagação os participantes foram questionados sobre o que perderiam caso o parque deixasse de existir. Sem quantificar os resultados, a autora observou que alguns entrevistados comentaram que não perderiam nada com o fim do parque. Outros abordaram a perda de conhecimento e cultura, além da história e do patrimônio arqueológico. Como os entrevistados não comentaram do patrimônio paleontológico nesta última questão, Souza (2009) afirmou que os conceitos arqueológicos são mais bem apreendidos do que os paleontológicos na região. Todavia, na primeira questão, o patrimônio paleontológico foi mais vezes citado em relação ao arqueológico.

Na presente pesquisa, verificou-se que os professores, que também são moradores da região, possuem um maior conhecimento dos objetos paleontológicos, mesmo que equivocados em alguns instantes, em relação aos arqueológicos. A grande maioria dos professores (87\%) sabia da existência de fósseis na bacia sedimentar, enquanto que $88 \%$ nunca ouviu falar dos vestígios do homem pré-histórico em São José de Itaboraí. Contudo, os resultados da pesquisa de Souza (2009) não podem 


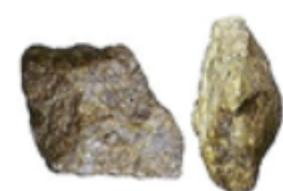

Raspadores maciços e espessos
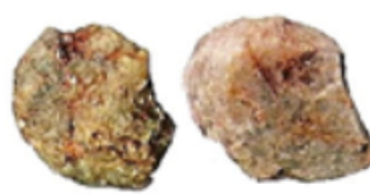

Raspadores

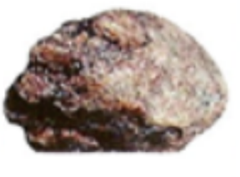

Perfuradores
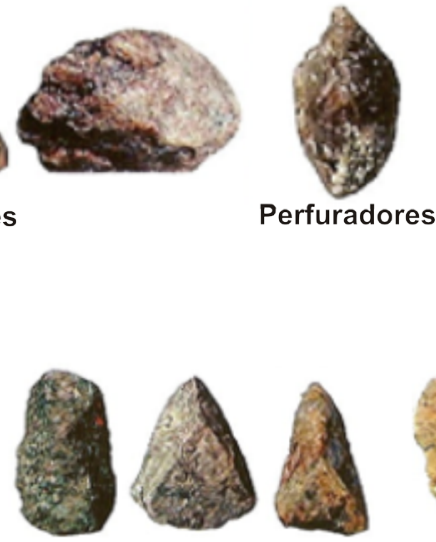

Lascas "Levallois"

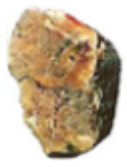

Faca

Figura 9 Artefatos utilizados pelo homem pré-histórico achados na Bacia de São José de Itaboraí no sítio arqueológico Morro da Dinamite (Modificado de Bergqvist et al. 2006).

ser desconsiderados, na medida em que a amostragem do estudo foi diferenciada.

$\mathrm{Na}$ figura 8 repara-se que apenas quatro citações (50\% das 8 citações de 7 entrevistados) dos professores referem-se à existência de artefatos líticos, enquanto que, se analisarmos a figura 6 , referente ao conhecimento dos professores em relação aos fósseis existentes na bacia sedimentar, verifica-se que uma série de fósseis foi citada e muitos de maneira correta. Isso comprova o pouco conhecimento que os entrevistados possuem em relação aos objetos arqueológicos encontrados em São José de Itaboraí se comparados com os objetos paleontológicos.

No entanto, pelos resultados obtidos, pode-se afirmar, assim como observado em Souza (2009), que os entrevistados fazem confusão entre os conceitos de História/Arqueologia/Paleontologia. Nesse contexto, inserem-se ainda conceitos de Geologia. Pela análise da figura 5 percebe-se que alguns professores consideraram fósseis como restos de organismos, rochas e vestígios humanos e, na figura 6 , relacionada aos tipos de fósseis encontrados em São José de Itaboraí, algumas citações referiram-se às rochas e artefatos humanos.

Dessa forma, acredita-se que, nos questionamentos de Souza (2009), os moradores da região explanaram, como possíveis perdas caso o parque deixasse de existir, o patrimônio arqueológico, em detrimento do paleontológico, na medida em que fazem confusão com os conceitos, ou seja, poderiam estar se referindo aos fósseis como patrimônio arqueológico, por exemplo. Entretanto, na questão referente aos valores do parque, como as respostas eram pré-definidas, o patrimônio paleontológico foi mais vezes citado em comparação ao arqueológico, mostrando maior apelo populacional direcionado aos fósseis, se comparados com os vestígios do homem pré-histórico.

\section{Iniciativas de conscientização populacional em relação ao patrimônio geológico}

Um bom exemplo de iniciativas de conscientização populacional em relação ao patrimônio geológico ocorre na cidade de Maravilha em Alagoas, através das unidades de educação patrimonial e ambiental. A capacitação dos professores e estudantes da rede pública, bem como da população local foi realizada utilizando a paleontologia como ferramenta, tornando-os agentes protetores e multiplicadores do conhecimento. As atividades consistiram na identificação, junto à comunidade, das habilidades voltadas para a confecção de artesanato, agregando valor à cultura local e na realização de uma reunião com as lideranças locais, aberta à população, no intuito de apresentar a relevância do patrimônio fossilífero, assim como o potencial de desenvolvimento econômico local. Diante da sensibilização populacional o gestor público municipal viabilizou a construção de esculturas em áreas públicas, como a réplica da preguiça gigante, tigre dente de sabre e toxodonte. As lixeiras da cidade foram padronizadas com a temática do projeto, as estradas de acesso foram pavimentadas e foram criados vídeos educativos para serem reproduzidos nas escolas e para a população do município, além da construção de um museu paleontológico para exposição dos acervos encontrados na região. Esse projeto vem contribuindo para a criação de um 
parque temático de paleontologia no município de Maravilha (Silva et al. 2011).

São medidas semelhantes a estas que necessitam ser realizadas na região do entorno do Parque Paleontológico de São José de Itaboraí e servem de modelo para a criação de identidade da população local, professores e estudantes com o patrimônio geológico e arqueológico. Os aspectos científicos de São José de Itaboraí são desconhecidos ou pouco abordados nas escolas e, a possibilidade de ter a comunidade, professores e estudantes como agentes de proteção do patrimônio cultural e natural acabam sendo perdida. Para preservar uma riqueza é preciso, antes de tudo, conhecê-la. Para a preservação dos fósseis, rochas e artefatos líticos do homem pré-histórico e para um verdadeiro desenvolvimento social e econômico da região do entorno do Parque Paleontológico de São José de Itaboraí, por meio do geoturismo, há inicialmente a necessidade de que as populações locais, em todos os seus segmentos, tenham consciência de seu patrimônio.

\section{Conclusões}

Mediante os resultados pôde-se ter uma melhor noção do conhecimento dos professores do entorno do Parque Paleontológico de São José de Itaboraí em relação aos aspectos geológicos, paleontológicos e arqueológicos da região.

Em relação à teoria educacional construtivista, o papel do professor calca-se em observar o aluno, investigar quais são os seus conhecimentos prévios, seus interesses e, a partir dessa bagagem, procurar apresentar diversos elementos para que o aluno construa seu conhecimento. No entanto, para os educadores do entorno do Parque Paleontológico de São José de Itaboraí, a contribuição para o correto entendimento dos alunos acerca do patrimônio geológico e arqueológico da região é uma difícil tarefa, pois analisando os resultados das entrevistas, percebeu-se que desconhecem a existência das rochas de interesse econômico na região, dos fósseis de grande apelo científico (mamíferos primitivos) e indicaram na pesquisa organismos fósseis inexistentes na região (dinossauros, peixes e insetos). Além disso, a imensa maioria não tem informação acerca dos vestígios do homem pré-histórico (artefatos líticos e uma fogueira). Contudo, mesmo assim, verificou-se que o patrimônio paleontológico é mais bem conhecido na região se comparado com o patrimônio arqueológico.
Dessa forma, existe a necessidade de conscientização dos professores e, consequentemente, das populações locais sobre a importância do patrimônio geológico e arqueológico de Itaboraí, tornando-se necessária maior reflexão sobre as medidas de valorização do patrimônio e linguagens de divulgação científica. As estratégias de conscientização realizadas com os estudantes do Colégio Estadual Visconde de Itaboraí (CEVI), por meio do projeto "jovens talentos", necessitam ser organizadas também com os estudantes dos colégios onde as entrevistas foram realizadas, além de outros colégios da região, com a participação massiva dos professores e população local no processo de aprendizagem. Torna-se necessário exercitar o olhar dos professores, alunos e moradores; isso só pode ser feito com explicações diretas de profissionais capacitados. Nesse sentido, as visitas de pesquisadores de universidades e instituições científicas às escolas, ou a realização de palestras e reuniões no parque paleontológico, com livre acesso da população, é um meio de urgência para que o projeto do parque paleontológico tenha sucesso.

\section{Agradecimentos}

A Antonio Carlos Sequeira Fernandes, Lilian Paglarelli Bergqvist e Maria Antonieta da Conceição Rodrigues pela leitura crítica do estudo. A Lucas Balsini Garcindo pela ajuda na elaboração das ilustrações. Aos professores das escolas públicas do entorno do Parque Paleontológico de São José de Itaboraí pela receptividade e contribuições positivas para a realização da pesquisa. O estudo contou com apoio do CNPq, CAPES e FAPERJ.

\section{Referências}

Beltrão M.C.M.C. 2000. Ensaio de Arqueogeologia. Rio de Janeiro: Zit Gráfica e Editora Ltda. 168p.

Bergqvist L.P., Mansur K.L., Rodrigues M.A., Rodrigues-Francisco B.H., Perez R.A.R., Beltrão M.C.M.C. 2008. Bacia São José de Itaboraí, RJ Berço dos mamíferos no Brasil. In: Winge M., Schobbenhaus C., Souza C.R.G., Fernandes A.C.S., Berbert-Born M., Queiroz E.T. eds. Sítios Geológicos e Paleontológicos do Brasil. URL: http:// www.unb.br/ig/sigep/sitio123/sitio123.pdf. Acesso: 25.09.2011.

Bergqvist L.P., Moreira A.L., Pinto D.R. 2006. Bacia de São José de Itaboraí 75 anos de História e Ciência. Rio de Janeiro: Serviço Geológico do BrasilCPRM. 81p. 
Carvalho I.S. 2000. Paleontologia. Rio de Janeiro: Interciência. $628 \mathrm{p}$.

Guerra A.T., Guerra A.J.T. 2009. Novo dicionário geológico-geomorfológico. Rio de Janeiro: Bertrand Brasil. $7^{\mathrm{a}}$ ed. 652p.

Klein V.C., Rodrigues-Francisco B.H. 1981b. A Formação de "bolas de areia" na Bacia Calcária de Itaboraí, Rio de Janeiro. An. Acad. Bras. Cienc., 53(1):143-146.

Klein V.C., Rodrigues-Francisco, B.H. 1981a. Aspectos sedimentares e estruturais na Bacia Calcária de São José de Itaboraí, Rio de Janeiro, e suas implicações para a Paleontologia. An. Acad. Bras. Cienc., , 53(1):135-142.

Marshall L.G. 1985. Geochronology and land-mammal biochronology of the transamerican faunal interchange. In: Stehli F.G., Webb S.D. eds. 1985. The great American biotic interchange. New York: Plenum. p. 49-85.

Paula-Couto C. 1949. Novas observações sobre a paleontologia e a geologia do depósito calcário fossilífero de São José de Itaboraí. DNPM, Div. Geol. Miner., v. 49, p. 1-13. (Notas Prel. Estudos).

Price L.I., Campos D.A. 1970. Fósseis pleistocênicos no Município de Itaboraí, estado do Rio de Janeiro. In: Congr. Bras. Geol., 24, Brasília, 1970. Anais..., Brasília: SBG. p. 355-358.

Rodrigues M.A.C., Medeiros Maria J.B., Rodrigues-Francisco B.H., Fiaux Rodrigues V.L. 2006. Preservação do Patrimônio Geológico e Paleontológico do Estado do Rio de Janeiro, utilizando o Projeto “Jovens Talentos”. In: Congr. Bras. Geol., 43, Aracaju, 2006. Resumos..., Aracaju: SBGeo. p. 87.

Santos W.F.S. 2010. Diagnóstico para o uso geoturístico do patrimônio geológico de São José de Itaboraí, Itaboraí (Estado do Rio de Janeiro): subsídio às estratégias de geoconservação. Rio de Janeiro: Inst. Geoc. UFRJ. 252p. (Dissert. Mestr.).

Santos W.F.S., Carvalho I.S. 2008. A importância do Museu dos Dinossauros no desenvolvimento socioespacial de Peirópolis - Uberaba (Minas Gerais): diagnóstico para o turismo paleontológico. Rev. Museu Nacional, 66(2):403-456.

Santos W.F.S., Carvalho I.S. 2011a. Propostas para conservação, valorização e divulgação do patrimônio geológico de São José de Itaboraí - Itaboraí, Estado do Rio de Janeiro (Brasil). In: Danyau M.S., Toro K.T. eds. Simp. Geoparques y Geoturismo en Chile, 1, Melipeuco, 2011. Actas..., Melipeuco. p. 135-138.

Santos W.F.S., Carvalho I.S. 2011b. Propostas para a preservação do Parque Paleontológico de São José de Itaboraí (Brasil) a partir da percepção populacional. An. Inst. Geoc. UFRJ, 34(2):24-37.

Santos W.F.S., Carvalho I.S. 2011c. Efeitos socioambientais do geoturismo segundo a percepção populacional: o caso de São José de Itaboraí (Itaboraí
- Estado do Rio de Janeiro). In: Congresso Brasileiro de Paleontologia, 22, Natal, 2011. Atas..., Natal, p. 133-136.

Santos W.F.S., Carvalho I.S. 2011d. Percepção da população local dos possíveis benefícios sociais do geoturismo frente à revitalização do Parque Paleontológico de São José de Itaboraí (Itaboraí - Estado do Rio de Janeiro). In: Congresso Brasileiro de Paleontologia, 22, Natal, 2011. Atas..., Natal, p. 148-152.

Santos W.F.S., Carvalho I.S. 2012a. Percepção Populacional dos Efeitos Socioeconômicos do Geoturismo: o Caso de São José de Itaboraí (Itaboraí, Estado do Rio de Janeiro). An. Inst. Geoc. UFRJ 35(1):242-251.

Santos W.F.S., Carvalho I.S. 2012b. Efeitos positivos e negativos da mineração em São José de Itaboraí, Itaboraí (Estado do Rio de Janeiro, Brasil). In: Henriques M.H., Andrade A.I., Quinta-Ferreira M., Lopes F.C, Barata M.T., Pena dos Reis R., Machado A. eds. 2012. Para Aprender com a Terra, Memórias e Notícias de Geociências no Espaço Lusófono. Imprensa Univ. Coimbra. Cap. 34, p. 321-330.

Santos W.F.S., Carvalho I.S. 2012c. Parque Paleontológico de São José de Itaboraí (Brasil): propostas para a preservação do patrimônio a partir das opiniões da população de Cabuçu. In: Henriques M.H., Andrade A.I., Quinta-Ferreira M., Lopes F.C., Barata M.T., Pena dos Reis R., Machado A. eds. 2012. Para Aprender com a Terra, Memórias e Notícias de Geociências no Espaço Lusófono. Imprensa Univ. Coimbra. Cap. 35, p. 331-340.

Santos W.F.S., Carvalho I.S. 2012d. Potenciais efeitos socioeconômicos do geoturismo na região do Parque Paleontológico de São José de Itaboraí: a perspectiva dos professores locais. In: Henriques M.H., Andrade A.I., Quinta-Ferreira M., Lopes F.C., Barata M.T., Pena dos Reis R., Machado A. eds. 2012. Para Aprender com a Terra, Memórias e Notícias de Geociências no Espaço Lusófono. Imprensa Univ. Coimbra. Cap. 36, p. 341-350.

Silva A.P.L., Silva J.L.L., Omena E.C., Oliveira Y.A.B. 2011. Atividades de Educação Patrimonial e Ambiental visando a Preservação dos Fósseis e da Caatinga no Alto Sertão de Alagoas. In: Congr. Bras. Paleont., 22, Natal, 2011. Atas, Natal, p. 123-125.

Souza A.R. 2009. Geoconservação e Musealização: a aproximação entre duas visões de mundo. Os múltiplos olhares para um patrimônio. Rio de Janeiro: UNIRIO/MAST. 155p. (Dissert. Mestr.).

Souza-Cunha F.L. 1982. A presença inédita de um mamífero Xenungulata no calcário da Bacia de São José de Itaboraí, RJ. An. Acad. Bras. Cienc., 54(4):754-755.

Velloso R., Almeida M.C.S. 2006. Plano de Diretrizes do Parque Municipal Paleontológico de São José de Itaboraí. Depto. Geol., Univ. Est. Rio de Janeiro. 46p. 